\title{
The Prediction of Contaminant Transport through Soil: A Novel Two- Dimensional Model Approach
}

Amin Chegenizadeh* Behzad Ghadimi and Hamid Nikraz

Civil Engineering Department, Curtin University, Australia

\begin{abstract}
The transport of contaminants has been a problematic issue for many years, mainly due to the adverse impact of the contaminants on the quality of groundwater. In order to analyse this, this study has developed a prediction model that allows the early detection of possible contamination. Firstly, the paper introduces the concept of the modelling of contamination transport through a soil matrix. Then it presents a two-dimensional Convection-Dispersion Equation (CDE) for contaminant transport in a soil matrix. This includes the investigation of different reaction coefficients and time-dependent inlet boundary conditions, from which a numerical solution is derived. The study also verifies recent previous work in this area through the use of numerical programming. The results for soil contamination in two dimensions are presented in this research.
\end{abstract}

Keywords: Contaminant transport; Novel two-dimensional model; Convection-dispersion equation; Hydraulic conductivity field; 2D numerical code modelling

\section{Introduction}

Contamination in soil may include different kinds of waste such as bacterial, chemical or radioactive waste. There is much concern regarding those wastes which are soluble in water and can therefore affect groundwater resources. There are two major methods applied in examining contaminant transport with regard to reactions in porous media. These methods are termed stochastic and deterministic [1-3]. Stochastic methods deal with reaction coefficients and are considered to 'be stationary processes' $[1,4-10]$, or they may be verified through a random hydraulic conductivity field $[1,11,12]$. As proper site-specific quantities are fundamental for simulation of contaminant transport, these models are expensive and unlikely to be used in practical cases [1]. The other approach is to analyse which of the deterministic methods could be simpler and more general compared to the stochastic methods [1] through considering two dimensions for the soil medium and the possibility of it being developed without Laplace transformation. One approach to consider deterministically is to model the soil medium as a layered system in which each layer has its own constant coefficients of reaction [13-18].

Besides the reaction processes, the behaviour of transported contaminants in soils is mainly influenced by inlet boundary conditions. The literature usually assumes aconstant source of inlet boundary conditions for solute transportation. Boundary conditions (BC) and reaction processes increase the complexity of stimulating contaminant transport in soils [1]. According to Gao et al. [1], there has so far been no study which has considered and provided a solution for the contaminant transport phenomenon with the three above mentioned factors combined. Flury et al. [2] have cited literature where analytical solutions were presented. However, adsorption and degradation were modelled separately in the Convection-Dispersion Equation (CDE), while in practice; adsorption and degradation can be simultaneous in contaminant transport in soils.

In recent work conducted by Gao et al. [1], a one-dimensional model was applied and an analytical solution derived. The study investigated a 1D CDE related to soil contaminant transport. An analytical solution is derived for the depth-dependent reaction coefficient, constant reaction coefficient and time-dependent inlet boundary condition. The solution manipulated the Laplace transform and the numerical inversion of that to obtain the actual solution in the time domain. The results are compared and the effect of each parameter is studied. Finally this study presents a few field application of the presented analytical solution for field herbicide and tracer leaching experiments.

Improvements to the numerical approach, such as programming $[19,20]$, have made it possible for this type of work tobe developed for 2D numerical code modelling. Moreover, a numerical solution may be more appropriate than an analytical solution for this problem. This study will focus on applying Matlab coding [21] to consider a new 2D numerical code, and will be conducted by the Geotechnical Research Group at Curtin University, Western Australia. A similar approach has been applied by Bresler E [22] to consider solute transportation using the implicit finite difference scheme. The current study uses the explicit finite difference and the equation is assumed to be uncoupled in horizontal and vertical directions. Yet it should be noted that in the development of the model there was an attempt to expand the previous simulation from one dimension to two dimensions, but this still could not come close to a real situation in which a variety of effective parameters and a three-dimensional situation must be considered.

The usual consideration for solute flux density is applying the continuum theory to solute transport, Parker and Genuchten [23] recommended that for one dimensional condition the following equation would be considered:

$$
\frac{\partial(\mathrm{Cr} \theta)}{\partial t}=-\partial J / \dot{\partial} X
$$

\section{Developed Mathematical Theory}

As outlined before, Gao et al. [1] considered a 1D model of contaminant transport in a soil matrix. This section presents a new $2 \mathrm{D}$ mathematical model. The mathematical model will be implemented in Matlab to generate valid and reliable data for use regarding contaminant transport in soil space.

*Corresponding author: $\mathrm{Dr}$ Amin Chegenizadeh, Civil Engineering Department, Curtin University, Perth, Australia, Tel: +618 92662491; E-mail: amin.chegenizadeh@curtin.edu.au

Received November 13, 2013; Accepted January 28, 2014; Published February 04, 2014

Citation: Chegenizadeh A, Ghadimi B, Nikraz H (2014) The Prediction of Contaminant Transport through Soil: A Novel Two-Dimensional Model Approach. J Civil Environ Eng 4: 138. doi:10.4172/2165-784X.1000138

Copyright: (c) 2014 Chegenizadeh A, et al. This is an open-access article distributed under the terms of the Creative Commons Attribution License, which permits unrestricted use, distribution, and reproduction in any medium, provided the original author and source are credited. 
The governing equation is a $2 \mathrm{D}$ Convection-Dispersion Equation (CDE).The equations are applied on the basis of constant water content, dispersion coefficient and velocity. The use of $2 \mathrm{D}$ analysis should assist researchers in finding out more about the nature of the transport of contaminants in soil.

$$
\begin{aligned}
& \frac{\partial c r}{\partial t}+\frac{\rho b}{\theta} \frac{\partial s}{\partial t}=D \frac{\partial^{2} c r}{\partial y^{2}}-\vartheta \frac{\partial c r}{\partial y}-\mu(y) c r \\
& \frac{\partial c r}{\partial t}+\frac{\rho b}{\theta} \frac{\partial s}{\partial t}=D \frac{\partial^{2} c r}{\partial x^{2}}-\vartheta \frac{\partial c r}{\partial x}-\mu(x) c r \\
& K_{d}(x)=K_{0}=\operatorname{Cosh}^{-2}\left(x / x^{0}\right) \\
& K_{d}(y)=K_{0}=\operatorname{Cosh}^{-2}\left(y / y^{0}\right) \\
& R(x) \frac{\partial c r}{\partial t}=D \frac{\partial^{2} c r}{\partial x^{2}}-\vartheta \frac{\partial c r}{\partial x}-\mu c r \\
& R(y) \frac{\partial c r}{\partial t}=D \frac{\partial^{2} c r}{\partial y^{2}}-\vartheta \frac{\partial c r}{\partial y}-\mu c r \\
& R(x)=1+\frac{\rho b K d(x)}{\theta} \\
& R(y)=1+\frac{\rho b K d(y)}{\theta}
\end{aligned}
$$

For the sake of simplicity, given that this work is dealing with the two-dimensional for the very first time, reaction factors are considered to be constant and occurring in a homogenous environment.

\section{Initial and Boundary Condition}

In this study, the finite space system applied is the same as that of Gao et al. [1] and the contamination is considered to be zero in origin. The principle of this assumption comes from Genuchten and Parker [23] who stated that in order to satisfy the criteria of balance requirement, equations 10 and 11 should be met (Danckwerts effluent boundary condition) [1].

$$
\begin{array}{lr}
C r(x, 0)=0 & 0 \leq x \leq L \\
C r(y, 0)=0 & 0 \leq y \leq L \\
\left.r\right|_{x=0}-\left.D \frac{\partial c r}{\partial x}\right|_{x=0}=\vartheta f_{(r)} & 0<t<\infty \\
\left.\vartheta C r\right|_{y=0}-\left.D \frac{\partial c r}{\partial x}\right|_{y=0}=\vartheta f_{(r)} & 0<t<\infty \\
\frac{\partial c r}{\partial x}(L, t)=0 & 0<t<\infty \\
\frac{\partial c r}{\partial y}(L, t)=0 & 0<t<\infty
\end{array}
$$

\section{Simulation Parameters}

A number ofparameters were considered to run the simulation. Most parameters selected were similar to those found in Gao et al. [1] and Flury et al. [2], the main reason being to ensure that the new steps verified past work. The simulation parameters are presented in Table 1.

\section{DCode Verification and Validation}

This section shows the verification process of the Matlab code by

\begin{tabular}{|l|c|c|}
\hline Parameters Description & Values & Symbol \\
\hline Finite spatial domain length & $250 \mathrm{~cm}$ & $\mathrm{~L}$ \\
\hline Volumetric water content & $0.4 \mathrm{~cm}^{3} / \mathrm{cm}^{3}$ & $\theta$ \\
\hline Bulk Density & $1.2 \mathrm{~g} / \mathrm{cm}^{3}$ & $\rho$ \\
\hline Average pore-water velocity & $20 \mathrm{~cm} / \mathrm{d}$ & $\mathrm{U}$ \\
\hline Hydrodynamic dispersion coefficient & $400 \mathrm{~cm}^{3} / \mathrm{g}$ & $\mathrm{D}$ \\
\hline Retardation factor in top soil & 2 & $\mathrm{R}$ \\
\hline Adsorption coefficient in topsoil & $1 / 3 \mathrm{~cm}^{3} / \mathrm{g}$ & $\mathrm{K}$ \\
\hline Observed time for concentration profiles & 5 day, $10 \mathrm{day}, 20$ day & $\mathrm{T}$ \\
\hline
\end{tabular}

Table 1: Simulation Parameters.

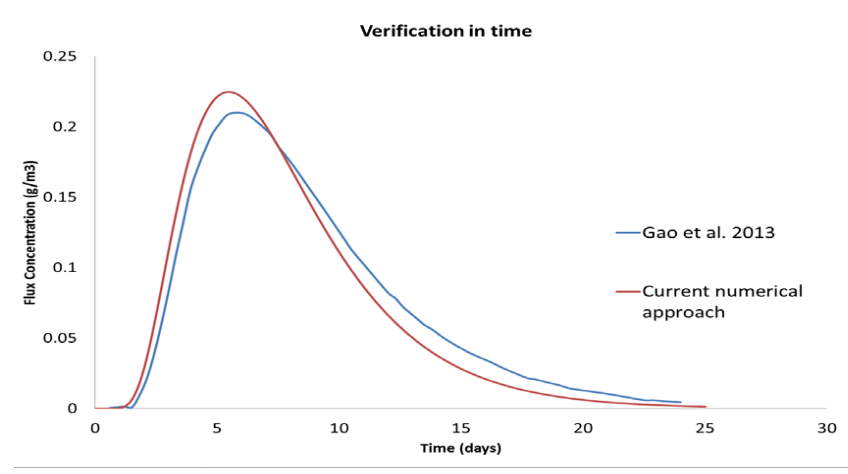

Figure 1: Verification in time.

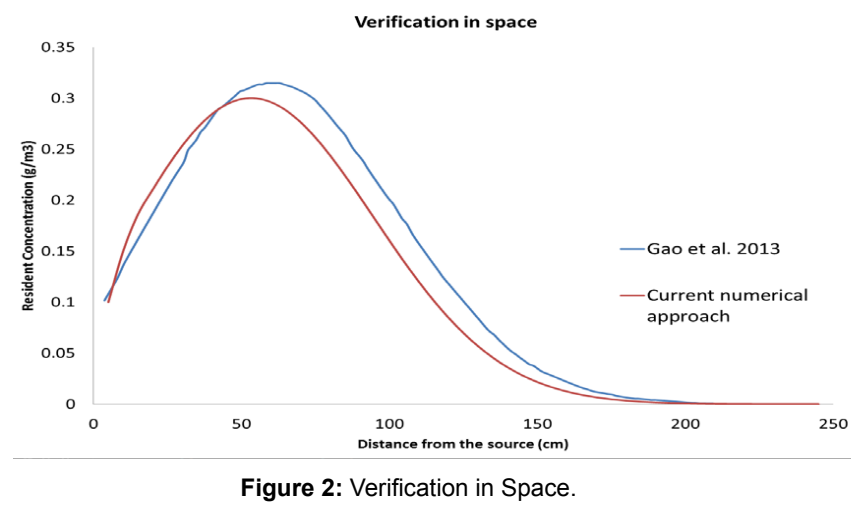

comparing the results to those presented by Gao et al. [1].

Figure 1 illustrates the flux concentration at $100 \mathrm{~cm}$ from the contamination coordinates. This is a verification of the numerical model with the analytical solution given in the time domain. Acceptable results are very close to those calculated by the analytical solution. The maximum difference is at five days when the peak occurred and the numerical solution resulted in $0.22 \mathrm{~g} / \mathrm{m}^{3}$ while the analytical solution was $0.21 \mathrm{~g} / \mathrm{m}^{3}$.

Figure 2 shows the resident concentration at Day 5 (where the maximum concentration occurs). Figure 2 verifies the numerical and analytical solution in the space domain. Once again, very acceptable responses are obtained here. The maximum difference occurred at the peak $(55 \mathrm{~cm}$ for numerical and $60 \mathrm{~cm}$ for analytical) where the numerical model resulted in $0.31 \mathrm{~g} / \mathrm{m}^{3}$ and the analytical solution was $0.32 \mathrm{~g} / \mathrm{m}^{3}$.

\section{Newly Developed 2D Model}

The idea of 2D modelling can now be applied after verification of the $1 \mathrm{D}$ model with examples from the literature. This section deals 
with implementing the $2 \mathrm{D}$ model in Matlab. The material properties used for the analysis were the same as those found in Gao et al. [1]. Due to the complexity of this phenomenon, a limited time and space analysis was applied. The space varied between $0 \mathrm{~m}$ and $2.5 \mathrm{~m}$ and the time varied between 0 and 25 days. In both the $\mathrm{X}$ (horizontal) and $\mathrm{Y}$ (vertical) directions, the coefficients were assumed to be equal. $\mu$ and $\mathrm{K}$ were considered to be depth independent and time independent, which is expressed mathematically: $\mu=\mu_{0}$ and $\mathrm{K}=\mathrm{K}_{0}$. Moreover, both the vertical and horizontal directions were assumed to have the same physical properties.

In order to obtain a better understanding of the effect of the degradation rate and the adsorption coefficient, the model was run for different values of field data; this data was taken from Vryzas et al. [24]. Assumptions were applied due to the complexity of the work, i.e., the reaction factors each time were one of the values taken from Vryzas et al. [24].The values are presented in Table 2.

\section{Results and Discussion}

This section consists of two parts. The first part deals with modelling and understanding the mechanism of the contamination transportation in a $2 \mathrm{D}$ soil medium and the second with studying the effects of various reaction coefficients.

\section{Mechanism of the contamination transportation in a 2Dsoil matrix}

Figures 3-5 presents the calculated contamination in 2D space over time. It is clear that with the change in time from five days to 10 days, the peak of contamination moves in the soil matrix, i.e., the peak is found in a different location (it has moved from the $(55,55)$ - $\mathrm{cm}$ coordinate to $(125,125)$-cm after 10 days and to $(225,225)$-cm after 25 days).

Maximum contamination occurs first somewhere close to the corner of contamination (the location of the contaminant is assumed to be found in the origin). Over time, this maximum moves towards the other diagonal corner and decreases in amount. Moreover the contours will expand in space. This means that the contamination is expanded in

\begin{tabular}{|c|c|c|}
\hline No. Case & K & $\boldsymbol{\mu}$ \\
\hline Case 1 & 0.33 & 0.2 \\
\hline Case 2 & 0.49 & 0.007 \\
\hline Case 3 & 1.08 & 0.014 \\
\hline
\end{tabular}

Table 2: Values of $k$ and $\mu$.

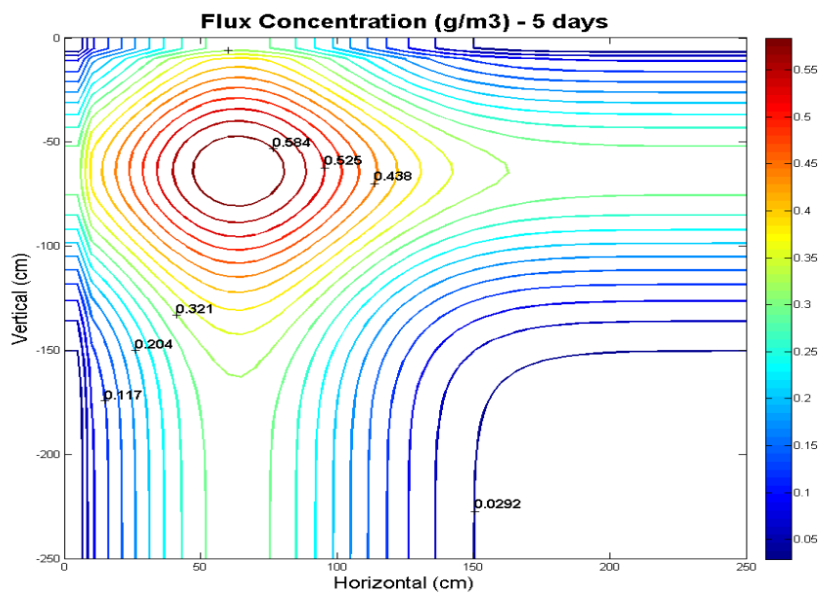

Figure 3: Case 1 - Flux Concentration - 5 Days.

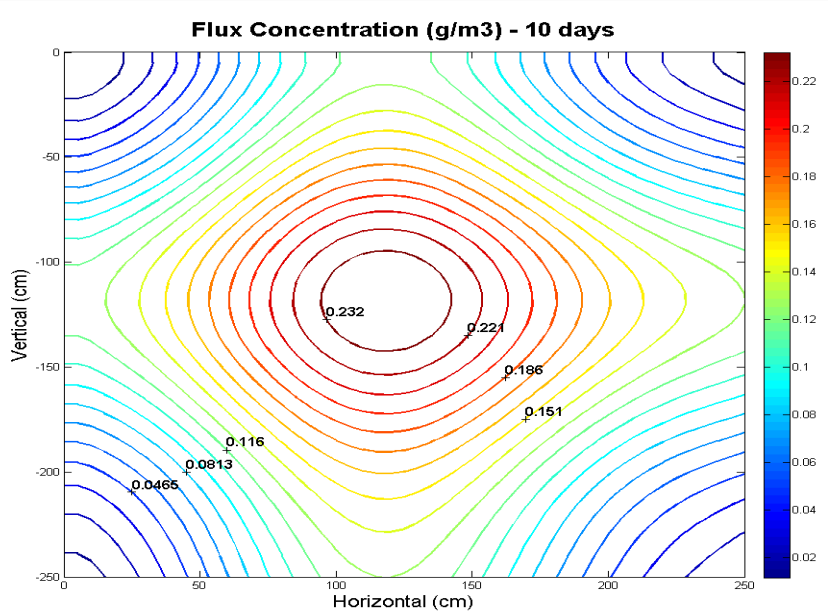

Figure 4: Case 1 - Flux Concentration - 10 Days.

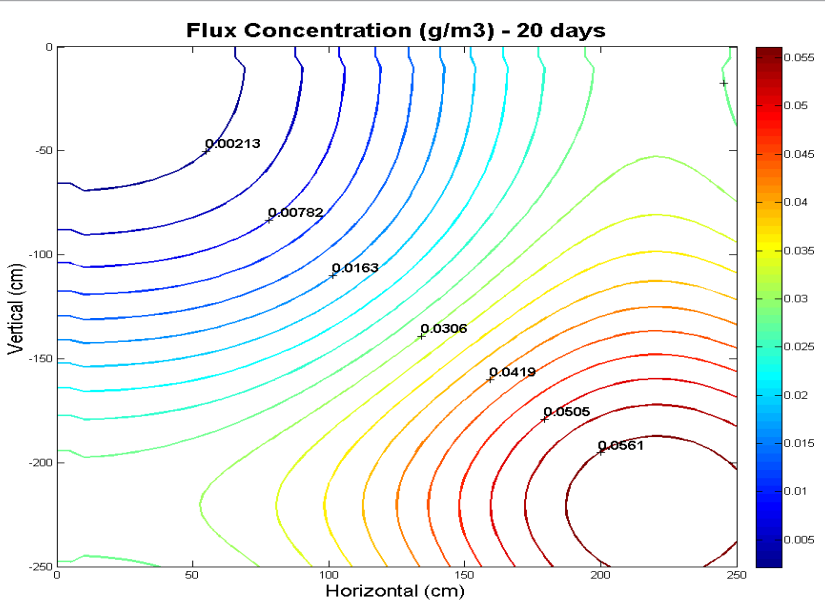

Figure 5: Case 1 - Flux Concentration - 20 Days.

space and decayed by time. This can only be observed in a 2D modelling as it is completely hidden in a $1 \mathrm{D}$ analysis.

The concentrated contaminant (the maximum amount) moves in a diagonal direction which it can be assumed is due to the same physical properties existing in both horizontal and vertical directions.

The results from the 2D modelling are presented in Figures 3-5. Figure 3 presents the flux concentration over five days. The contours clearly demonstrate the validity of the results and illustrate the mechanism of contamination movement in the soil matrix.

Figure 4 presents flux concentration after 10 days, which again confirms a similar mechanism to that illustrated in Figure 3. It can be observed that the concentration decreased and expanded in the space (the maximum has decreased from $0.613 \mathrm{~g} / \mathrm{m}^{3}$ to $0.243 \mathrm{~g} / \mathrm{m}^{3}$ and the contour lines are farther from each other).

Figure 5 presents the flux concentration after 20 days which shows the movement of contamination source to the corner of the domain. After these 20 days, the contamination is significantly decayed (from $0.613 \mathrm{~g} / \mathrm{m}^{3}$ to less than $0.1 \mathrm{~g} / \mathrm{m}^{3}$ ).

\section{Effect of reaction coefficients on the model}

The value of the reaction coefficient is considered to be constant and the soil matrix is considered to be homogenous. It is important to discuss the effect of different values on reaction factors. 


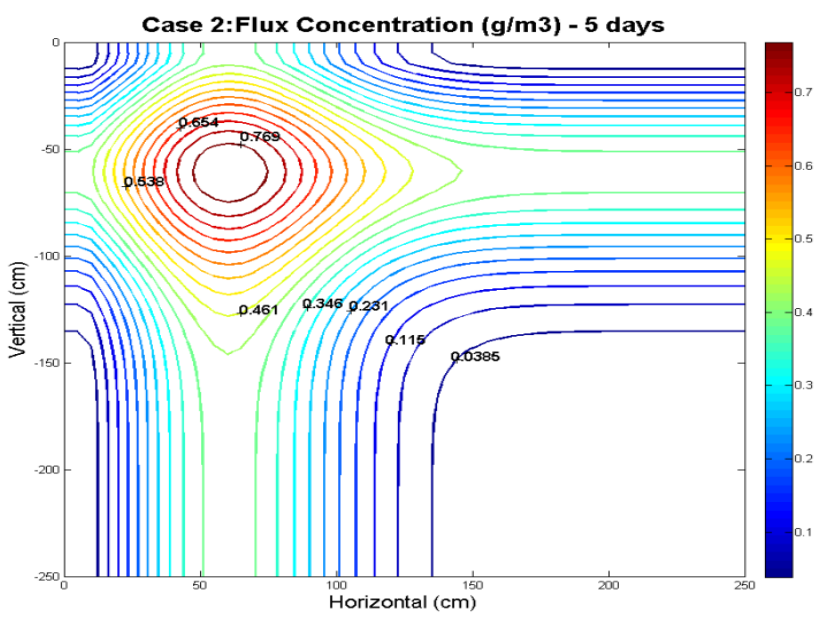

Figure 6: Case 2 - Flux Concentration - 5 Days.

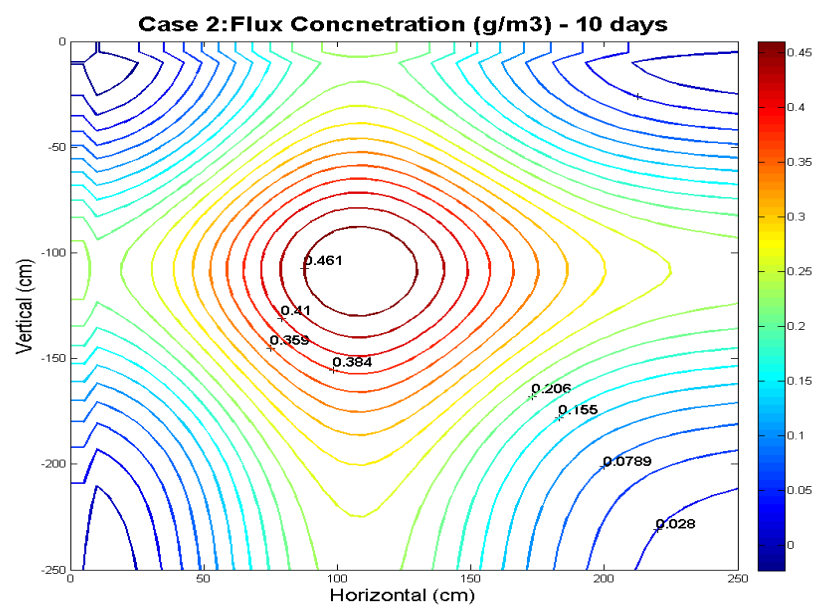

Figure 7: Case 2 - Flux Concentration - 10 Days.

For this reason, two more reaction factors were applied to the model, based on the field values obtained from Vryzas et al. [24]. The results showed agreement among three cases in the study.

One of the important indexes of contamination in our domain is the peak contours. The figures showed a peak of 0.584 in five days for Case 1, increasing to 0.769 in five days for Case 2 and 0.76 for Case 3. In the 10 day graph, the peak moved from 0.23 (Case 1) to 0.46 (Case2) and 0.41 (Case 3). In the 20 day graph, the peak increases from 0.05 to 0.2 and then decreases to 0.05 again. This means that the effects of the combination of the reaction factors upon the mechanism cannot be predicted as a linear trend and the interaction effects between them can be comprehended only through numerical modelling or an analytical solution (Figure 6-11).

Table 3 presents the changes in peak in contours based on time (i.e. five days, 10 days and 20 days) and cases (i.e. Cases 1-3).This brief parametric study confirms the effect of reaction factors on peak place in domain and also peak values. For instance, after five days, while the reaction factors for Case 1 ( 0.33 (adsorption coefficient) and 0.2 (degradation coefficient)), the peak happens at $x=55 \mathrm{~cm}, y=55 \mathrm{~cm}$ in the space domain and the value is $0.613 \mathrm{~g} / \mathrm{m}^{3}$, while for the second case with 0.49 (adsorption coefficient) and 0.007 (degradation coefficient), the peak happens at $\mathrm{x}=65 \mathrm{~cm}, \mathrm{y}=65 \mathrm{~cm}$. For Case 3 with 1.08 (adsorption coefficient) and 0.014 (degradation coefficient), the peak will happen at

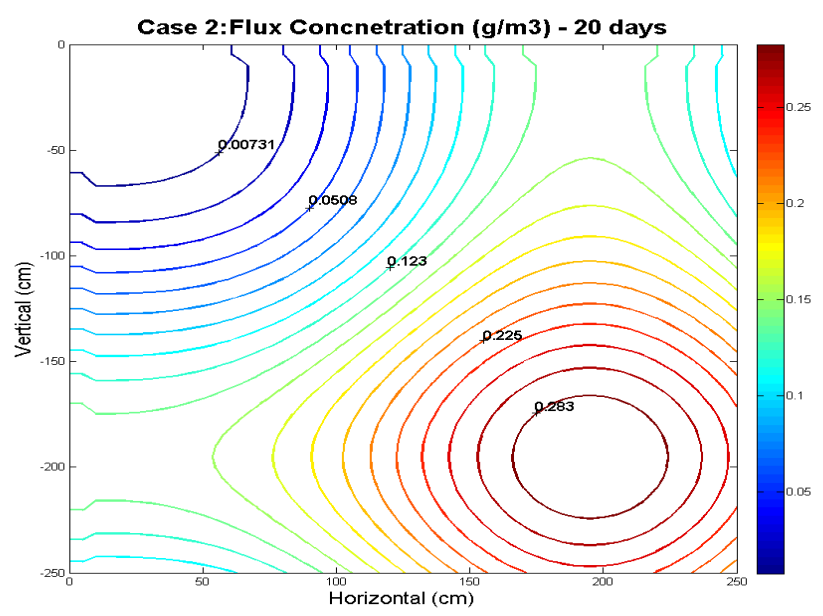

Figure 8: Case 2 - Flux Concentration - 20 Days.

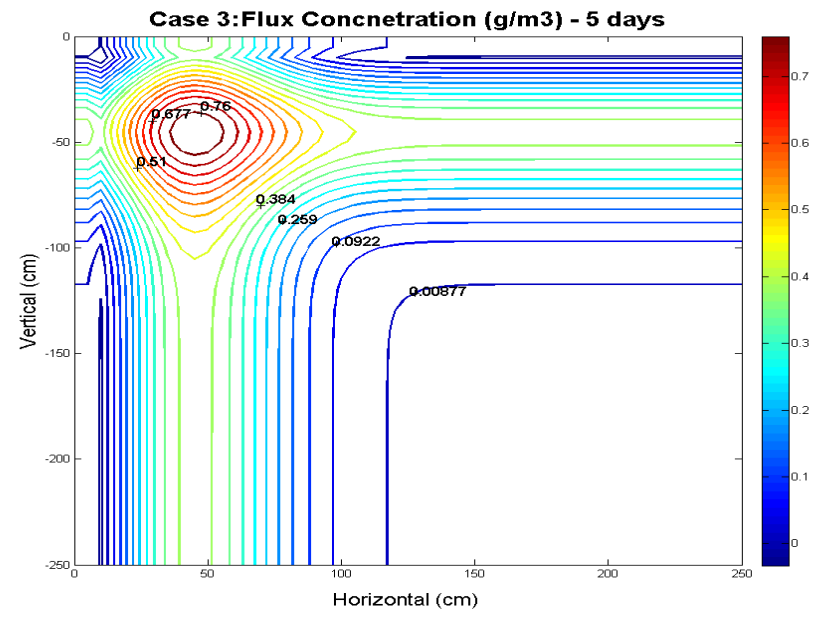

Figure 9: Case 3 - Flux Concentration - 5 Days.

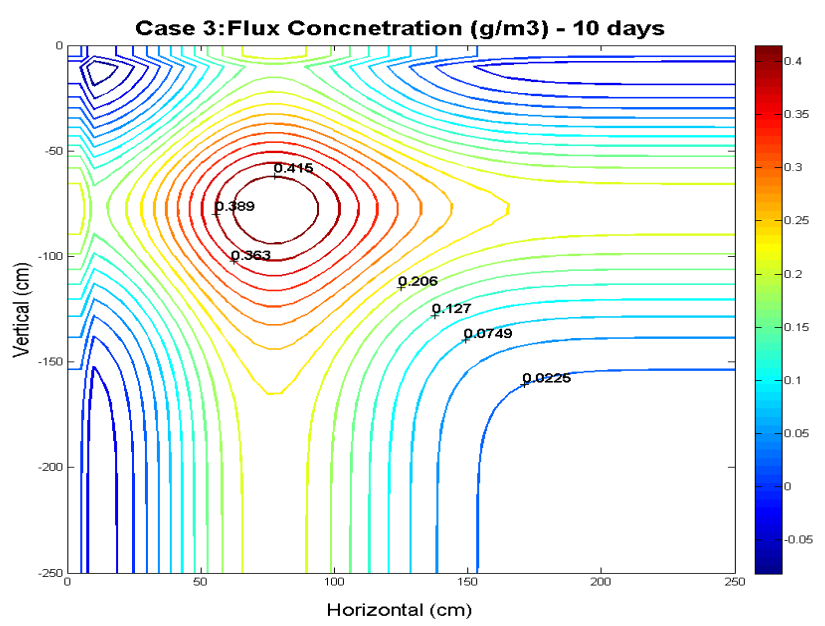

Figure 10: Case 3 - Flux Concentration - 10 Days. 
Citation: Chegenizadeh A, Ghadimi B, Nikraz H (2014) The Prediction of Contaminant Transport through Soil: A Novel Two-Dimensional Model Approach. J Civil Environ Eng 4: 138. doi:10.4172/2165-784X.1000138

Page 5 of 6

$\mathrm{x}=46 \mathrm{~cm}, \mathrm{y}=46 \mathrm{~cm}$. A similar trend can be seen for the other times (i.e. 10 days and 20 days).

\section{Conclusion}

This research presented a newly developed 2D mathematical equation and a numerical modelling of contaminant transport in soil by applying a $2 \mathrm{D}$ convection-dispersion equation (CDE). The modelled monstrated the capacity to cover the results of $1 \mathrm{D}$ modelling in the verification step and then was extended to the $2 \mathrm{D}$ domain. The numerical modelling of the 1D model alone, with a new approach to obtain better and quicker results compared to the analytical approach done by Gao et al. [1], makes a significant impact on the fieldof contaminant transport. However, the authors believe that a lot can be done in the 2D domain, and continued research at Curtin University is expected to offer more in this area.

This study has shown the improvements in the simulation of the transport of contaminants arising from using a $2 \mathrm{D}$ convectiondispersion equation (CDE). It has also authenticated the $1 \mathrm{D}$ model presented by Gao et al. [1] by using a highly advanced coding and computer program rather than an analytical solution which can cause complexity in interpreting results [1]. When similar assumptions to those made by Gao et al. [1] were examined in this study, the research was easily able to verify their latest work in this area.

This study examined contaminant transport in soil according to a specific boundary condition (i.e. time-dependent) and with the assumption of reaction coefficients being constant. The adsorption coefficient and degradation rate applied were based on the field data of Vryzas et al. [24].The results describe the movement of contaminant through a soil matrix. Further study is required to consider a threedimensional soil medium including the variation of effective parameters and this is the scope of ongoing research at Curtin University.

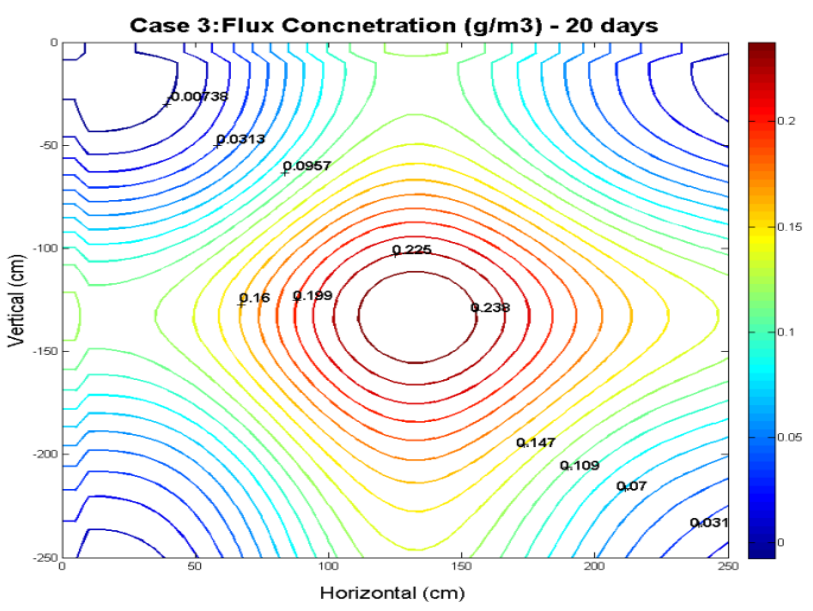

Figure 11: Case 3 - Flux Concentration - 20 Days.

\section{Acknowledgment}

The authors would like to appreciate Mr Saeid Amiralian for helping in editing of the article.

\section{Nomenclature}

- $\quad \mathrm{C}_{\mathrm{r}}$ : The resident solute concentration $\left(\mathrm{ML}^{-3}\right)$

- $\quad \mathrm{S}:$ The sorbed concentration $\left(\mathrm{MM}^{-1}\right)$

- $\quad \theta$ : The volumetric water content

- $\quad$ D: The hydrodynamic dispersion coefficient $\left(\mathrm{L}^{2} \mathrm{~T}^{-1}\right)$

- $\quad \mathrm{u}: T h e$ average pore-water velocity $\left(\mathrm{LT}^{-1}\right)$

- $\quad \rho b$ : The soil bulk density $\left(\mathrm{ML}^{-3}\right)$

- $\quad \mu$ : The degradation rate $\left(\mathrm{T}^{-1}\right)$

- $\mu(\mathrm{x})$ : The depth-dependent degradation rate $\left(\mathrm{T}^{-1}\right)$

- $\mu(\mathrm{y})$ : The depth-dependent degradation rate $\left(\mathrm{T}^{-1}\right)$

- $\quad$ x: Spatial coordinate (L)

- $\quad y$ : Spatial coordinate (L)

- $\quad t$ time $(T)$

- $\quad \mathrm{K}_{\mathrm{d}}$ : The constant adsorption coefficient $\left(\mathrm{M}^{-1} \mathrm{~L}^{3}\right)$

- $\quad \mathrm{K}_{d}(\mathrm{X})$ : The depth-dependent adsorption coefficient $\left(\mathrm{M}^{-1} \mathrm{~L}^{3}\right)$

- $\quad \mathrm{K}_{d}(\mathrm{y})$ : The depth-dependent adsorption coefficient $\left(\mathrm{M}^{-1} \mathrm{~L}^{3}\right)$

- $\mathrm{K}_{0}$ : The adsorption coefficient rate in the topsoil $\left(\mathrm{M}^{-1} \mathrm{~L}^{3}\right)$

- $\mathrm{R}$ : The variable retardation factor $(x, y)$

- $\mathrm{J}$ : is flux density

\section{References}

1. Gao G, Fu B, Zhan H, Ma Y (2013) Contaminant transport in soil with depthdependent reaction coefficients and time-dependent boundary conditions. Water research 47:2507-2522.

2. Flury M, Wu QJ, Wu L, Xu L (1998) Analytical solution for solute transport with depth-dependent transformation or sorption coefficients. Water Resources Research 34: 2931-2937.

3. Kia SF (1991) Subsurface multiphase flow of organic contaminants: Model development and validation. Water Research 25: 1225-1236.

4. Chrysikopoulos CV, Kitanidis PK, Roberts PV (1990) Analysis of onedimensional solute transport through porous media with spatially variable retardation factor. Water Resources Research 26: 437-446.

5. Loll P, Moldrup P (2000) Stochastic analyses of field-scale pesticide leaching risk as influenced by spatial variability in physical and biochemical parameters. Water Resources Research 36: 959-970.

6. Sleep BE, McClure PD (2001) Removal of volatile and semi volatile organic contamination from soil by air and steam flushing. Journal of Contaminant Hydrology 50: 21-40.

7. Deceuster J, Kaufmann O (2012) Improving the delineation of hydrocarbon impacted soils and water through induced polarization (IP) tomographies: a field study at an industrial waste land. Journal of Contaminant Hydrology 136 25-42.

8. Bonten LT, Kroes JG, Groenendijk P, Grift BVD (2012) Modeling diffusive $\mathrm{Cd}$ and $\mathrm{Zn}$ contaminant emissions from soils to surface waters. Journal of Contaminant Hydrology 138-139: 113-122.

9. Nguyen V T, Zhao L, Zytner RG (2013) Three-dimensional numerical model for soil vapor extraction. Journal of Contaminant Hydrology 147: 82-95.

\begin{tabular}{|c|c|c|c|c|c|c|}
\hline \multirow[b]{3}{*}{ Case Number } & \multicolumn{6}{|c|}{ Time (day) } \\
\hline & \multicolumn{2}{|c|}{ After 5 days } & \multicolumn{2}{|c|}{ After 10 days } & \multicolumn{2}{|c|}{ After 20 days } \\
\hline & Peak flux $\left(\mathrm{g} / \mathrm{m}^{3}\right)$ & $X-Y(\mathrm{~cm})$ & Peak flux $\left(\mathrm{g} / \mathrm{m}^{3}\right)$ & $X-Y(\mathrm{~cm})$ & Peak flux $\left(\mathrm{g} / \mathrm{m}^{3}\right)$ & $X-Y(\mathrm{~cm})$ \\
\hline Case 1 & 0.613 & 55,55 & 0.243 & 125,125 & 0.059 & 225,225 \\
\hline Case 2 & 0.808 & 65,65 & 0.486 & 115,115 & 0.297 & 200,200 \\
\hline Case 3 & 0.802 & 45,45 & 0.442 & 90,90 & 0.250 & 140,140 \\
\hline
\end{tabular}

Table 3: Peak of contamination in each case. 
Citation: Chegenizadeh A, Ghadimi B, Nikraz H (2014) The Prediction of Contaminant Transport through Soil: A Novel Two-Dimensional Model Approach. J Civil Environ Eng 4: 138. doi:10.4172/2165-784X.1000138

10. Santos DRS, Cambier P, Mallmann FJK, Labanowski J, Lamy I et al., (2012) Prospective modeling with Hydrus-2D of 50years $\mathrm{Zn}$ and $\mathrm{Pb}$ movement in low and moderately metal-contaminated agricultural soils. Journal of Contaminant Hydrology 145:54-66.

11. Miralles-Wilhelm F, Gelhar LW (1996a) Stochastic analysis of sorption macrokinetics in heterogeneous aquifers. Water Resources Research 32 1541-1549.

12. Miralles-Wilhelm F, Gelhar LW (1996b) Stochastic analysis of transport and decay of a solute in heterogeneous aquifers. Water Resources Research 32(12): 3451-3459.

13. Wu YS, Kool JB, Huyakorn PS, Saleem ZA (1997) An analytical model for nonlinear adsorptive transport through layered soils. Water Resources Research 33: 21-29.

14. Vanderborght $\mathrm{J}$, Vereecken $\mathrm{H}$ (2007) One-dimensional modeling of transport in soils with depth-dependent dispersion, sorption and decay. Vadose Zone Journal 6: 140-148

15. Bumgarner JR, McCray JE (2007) Estimating biozone hydraulic conductivity in wastewater soil-infiltration systems using inverse numerical modeling. Water Research 41(11): 2349-2360.

16. Wang P, Keller AA (2008) Soil particle-size dependent partitioning behavior of pesticides within water-soil-cationic surfactant systems. Water Research 42 : 3781-3788.

17. Lewis J, Sjöstrom J (2010) Optimizing the experimental design of soil columns in saturated and unsaturated transport experiments. Journal of Contaminant Hydrology 115: 1-13.

18. Schaefer CE, Arands RR, Van der Sloot HA, Kosson DS (1997) Modeling of the gaseous diffusion coefficient through unsaturated soil systems. Journal of Contaminant Hydrology 29: 1-21.

19. Stedmon CA, Seredyńska-Sobecka B, Boe-Hansen R, Le Tallec N, Waul CK et al., (2011) A potential approach for monitoring drinking water quality from groundwater systems using organic matter fluorescence as an early warning for contamination events. Water Research45: 6030-6038.

20. Periago EL, Delgado AN, Diaz-Fierros F (2000) Groundwater contamination due to cattle slurry: modelling infiltration on the basis of soil column experiments. Water Research 34: 1017-1029.

21. MatLab version 7.11.0.584 Curtin Licence number: 56781 .

22. Bresler E (1975) Two-dimensional transport of solutes during nonsteady infiltration from a trickle source. Soil Science Society of America Journal 39: 604-613.

23. Parker JC, Van Genuchten MT (1984) Flux-averaged and volume-averaged concentrations in continuum approaches to solute transport. Water Resources Research 20: 866-872.

24. Vryzas Z, Papadakis EN, Papadopoulou-Mourkidou E (2012) Leaching of $\mathrm{Br}$, metolachlor, alachlor, atrazine, deethylatrazine and deisopropylatrazine in clayey vadoze zone: A field scale experiment in north-east Greece. Water Research 46: 1979-1989. 